\title{
Gamma radiation mediated green synthesis of gold nanoparticles using fermented soybean-garlic aqueous extract and their antimicrobial activity
}

\author{
Ahmed Ibrahim El-Batal ${ }^{1 *}$, Abd-Algawad M Hashem² and Noha M Abdelbaky ${ }^{1}$
}

\begin{abstract}
Aspergillus oryzae was used to enhance the mobilization of antioxidants of soybean matrix along with garlic as a co-substrate by modulating polyphenolic substances during solid-state fermentation. Mobilized polyphenols were used as a green tool for synthesis and stabilization of gold nanoparticles (AuNPs). The radiation-induced AuNPs synthesis is a simple, clean and inexpensive process which involves radiolysis of aqueous solution that provides an efficient method to reduce metal ions. Gamma irradiated aqueous extract of fermented soybean and garlic was used for rapid preparation of AuNPs combining both effects of radiolytic reactions by radiation and stabilization by bioactive components of fermented extract. The synthesized AuNPs were confirmed by UV-Visible spectrophotometry, dynamic light scattering (DLS), Fourier Transform infra red (FT-IR) spectrophotometry, and transmission electron microscope (TEM) analysis which revealed morphology of spherical AuNPs with size ranging from 7-12 nm. The synthesized AuNPs exhibited antimicrobial activity against both Gram positive and Gram negative bacteria, as measured by well diffusion assay.
\end{abstract}

Keywords: Solid state fermentation, Soybean, Garlic, Gamma radiation, Gold nanoparticles, Antimicrobial activity

\section{Introduction}

Gold is a well known biocompatible metal and colloidal gold was used as a drinkable solution that exerted curative properties for several diseases in ancient times (Daniel and Astruc 2004) and now, because of its low cytotoxicity (Shukla et al., 2005), AuNPs have been widely used as the platform material in the field of biodiagnostics (Nam and Thaxton 2003), drug/DNA delivery (Paciotti et al., 2004), (Prow et al., 2006) cell imaging (Bielinska et al., 2002), immunostaining (Roth 2003), biosensing (Penn et al., 2003) and electron microscopy markers (Baschong and Stierhof 1998).

Solid state fermentation (SSF) of an edible plant matrix by filamentous fungi is a biotechnological strategy that may induce health beneficial naturally occurring antioxidant components including polyphenols during microbial fermentation (McCue and Shetty, 2005, Lee et al., 2008). As soybean contains phenolic and

\footnotetext{
*Correspondence: aelbatal2000@gmail.com

${ }^{1}$ Drug Radiation Research Department, National Center for Radiation Research \& Technology (NCRRT), P.O. Box 29, Nasr City, Cairo, Egypt Full list of author information is available at the end of the article
}

isoflavonoid compounds concentrated mainly in seed matrix, it is possible that the fungi can play role in mobilization of polyphenolic compounds during SSF period (McCue et al., 2003; McCue and Shetty, 2005, Huang et al., 2008, Bhanja et al., 2009). Isoflavonoids are polyphenolic compounds acting as reducing agents (free radical terminators), metal chelators and singlet oxygen quenchers (Mathew \& Abraham 2006), which suggests the reduction and stabilization of AuNPs. Garlic also is a rich source of the proteins, free amine groups and cysteine residues. These compounds contains functional groups that play a role in reducing and hence synthesis as well as stabilization of nanoparticles (Gole et al. 2001, Tortora et al. 2004) or via electrostatic attraction of negatively charged carboxylic groups (Rastogi and Arunachalam 2011) and therefore, stabilization of these nanoparticles by "capping".

The radiation-induced synthesis is one of the most promising strategies (Mostafavi et al. 1993). The process is simple, clean and has harmless feature (Li et al. 2007). The formation of AuNPs can be attributed to the radiolytic reduction which generally involves radiolysis of 


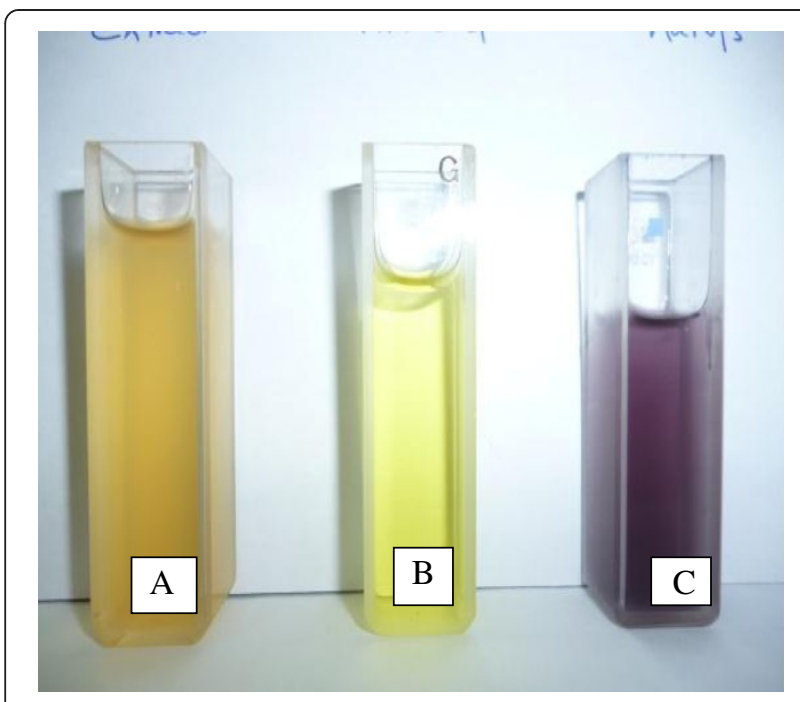

Figure 1 Photographic image shows the color of: $A=$ Aqueous extract, $B=\mathrm{HAuCl} 4, \mathrm{C}=\mathrm{AuNPs}$ i.e. $(\mathrm{A}+\mathrm{B})$.

aqueous solutions that provides an efficient method to reduce metal ions. In the radiolytic method, when aqueous solutions are exposed to gamma rays, they create solvated electrons, which reduce the metal ions and the metal atoms eventually coalesce to form aggregates (Marignier et al. 1985). The combined effect of both radiolytic reduction and presence of soybean flavonoids, and sulfur containing compounds and proteins in garlic resulted in formation of AuNPs by radiolytic reactions

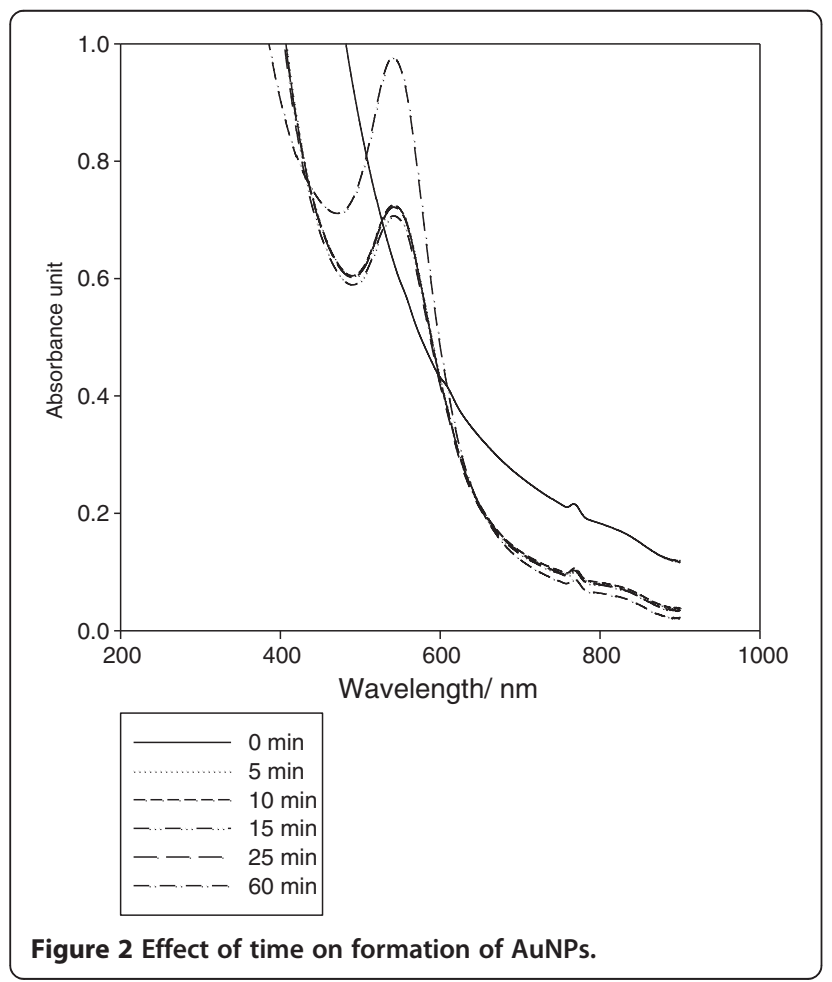

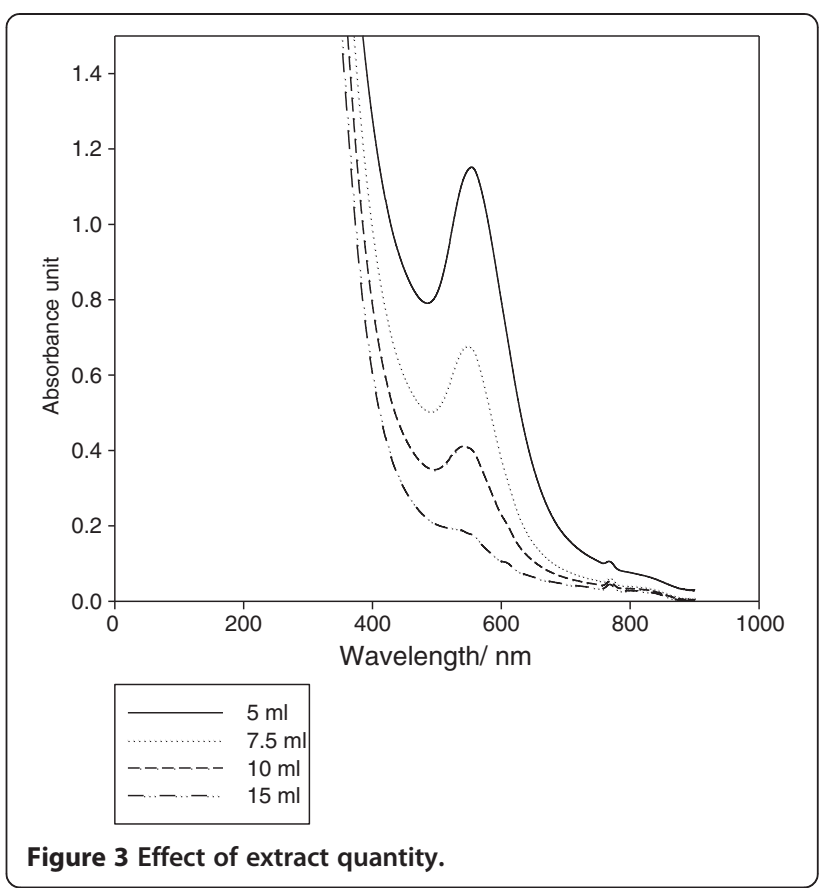

and stabilization by prevention of aggregates formation by "capping".

The antimicrobial activity of the synthesized AuNPs was assessed using agar well diffusion method against both Gram negative and positive bacteria and showed a good antimicrobial potential.

\section{Materials and methods}

\section{Materials}

All chemicals were purchased from Sigma-Aldrich.

Aspergillus oryzae was isolated and maintained on potato dextrose agar (PDA) plates at $4^{\circ} \mathrm{C}$. Cultures were reactivated by transferring onto fresh PDA slants and cultured at $20^{\circ} \mathrm{C}-22^{\circ} \mathrm{C}$ for $7-10$ days.

Commercial soybean seeds were obtained from the local market. The soybean seeds were ground to 30-mesh powders screen using a grinder and used along with garlic powder obtained from local market.

\section{Media and cultivation}

In an Erlenmeyer flask $(250 \mathrm{ml}), 5 \mathrm{gm}$ of crushed soybean seeds and $5 \mathrm{gm}$ of garlic powder were added along with $10 \mathrm{ml}$ of distilled water ( $\mathrm{pH} \mathrm{6.5)}$. The material was autoclaved at $121^{\circ} \mathrm{C}$ for 20 minutes. The spores were then harvested and suspended in $0.85 \%$ saline containing $0.1 \%$ Tween-80. The substrate was inoculated using $1 \mathrm{ml}$ of spore suspension $\left(9 \times 10^{6}\right.$ spores $\left./ \mathrm{ml}\right)$ for 6 days with moisture content $60 \%$ at $35^{\circ} \mathrm{C}$. 


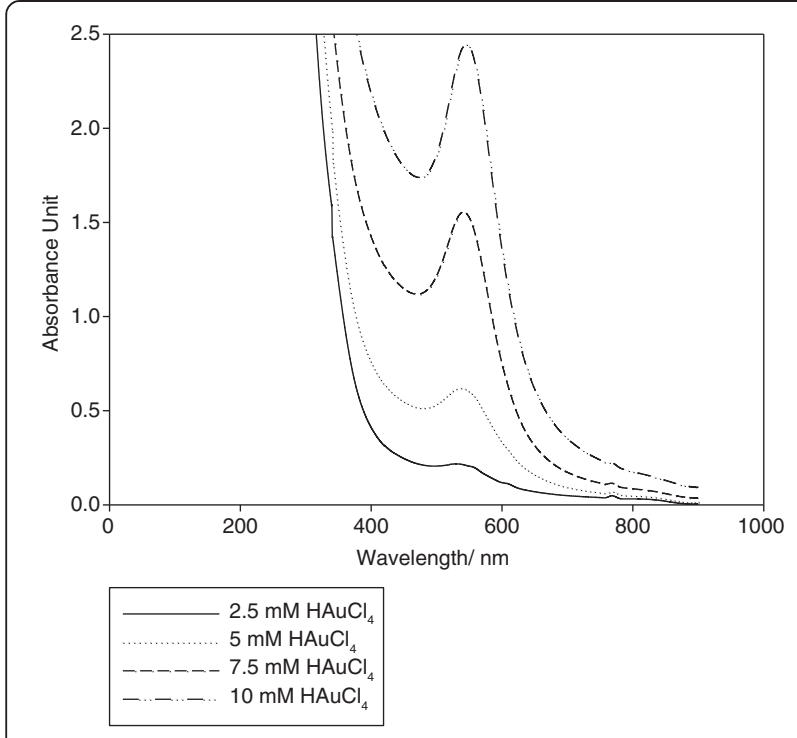

Figure 4 Effect of $\mathrm{HAuCl} 4$ concentration on formation of AuNPs.

\section{Preparation of fermented extracts}

The fermented product was extracted with ethanolic solution $95 \%(1: 10, \mathrm{w} / \mathrm{v})$ with gentle shaking $100 \mathrm{rpm}$, at room temperature for 2 hours using (LAB-Line ${ }^{\circledR}$ Orbit Environ) shaker. The filtrate was then decanted and centrifuged using (Hettich Universal 16R cooling centrifuge) at $6,000 \mathrm{rpm}$ for 10 minutes at $6^{\circ} \mathrm{C}$. The resulted ethanolic extract is used for further analysis. For preparation of aqueous extract, the ethanolic extracts were vacuum concentrated and dried using freeze-dryer (LyoTrap USA). The resulted powder was redispersed in equal amount of water and used for further analysis.

\section{Preparation and characterization of AuNPs}

AuNPs were prepared according to the method described by (Song and Kim 2009, Noruzi et al., 2011). Briefly, to different volumes $(5,7.5,10$ and $15 \mathrm{ml})$ of fermented extract, containing total phenols $0.272 \mathrm{mg} /$ $\mathrm{ml}$ expressed as gallic acid equivalent, different concentrations of tetrachloroauric acid $(2.5,5,7.5$ and $10 \mathrm{mM})$ were added, (purity of $49 \%$ gold metal). The reaction mixture is stirred properly using magnetic stirrer with heating at $75^{\circ} \mathrm{C}$, within 1 minute the yellow colored solution started changing to pink then violet detected

Table 1 Effect of temperature on time taken for color conversion i.e. formation of AuNPs

\begin{tabular}{ll}
\hline Temperature $/{ }^{\circ} \mathrm{C}$ & Time/minutes \\
\hline 25 & 120 \\
\hline 50 & 21 \\
\hline 75 & 3 \\
\hline 100 & 0.67 \\
\hline
\end{tabular}

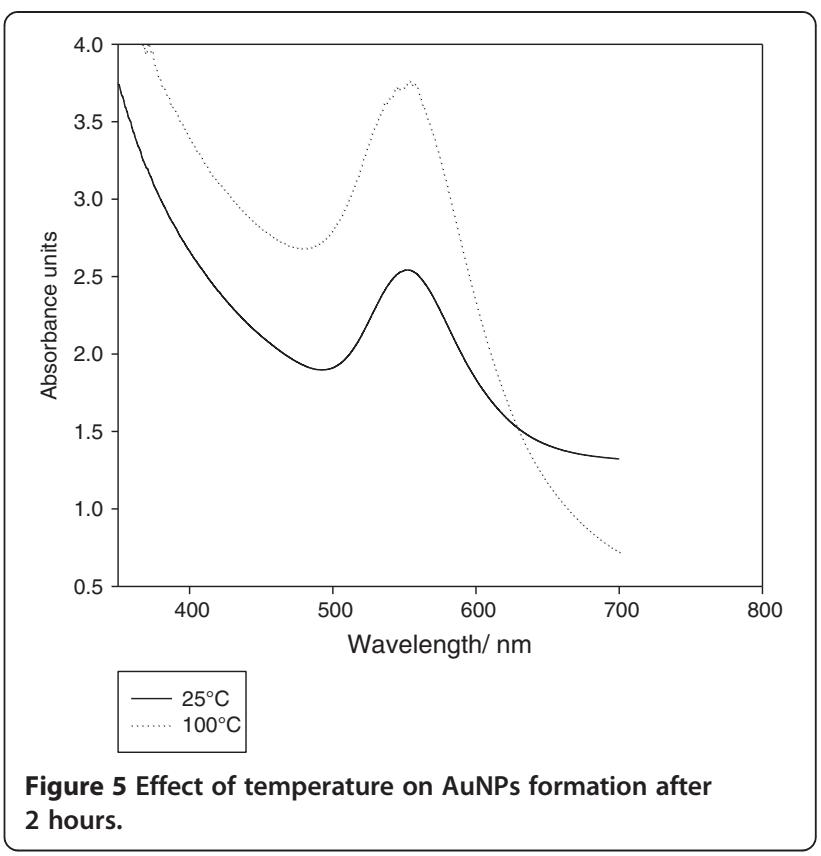

visually and by UV-Visible spectrophotometer indicating the formation of AuNPs.

UV/Vis spectra of AuNPs were recorded as a function of wavelength using JASCO V-560 UV/Vis spectrophotometer from $200-700 \mathrm{~nm}$ operated at a resolution of $1 \mathrm{~nm}$.

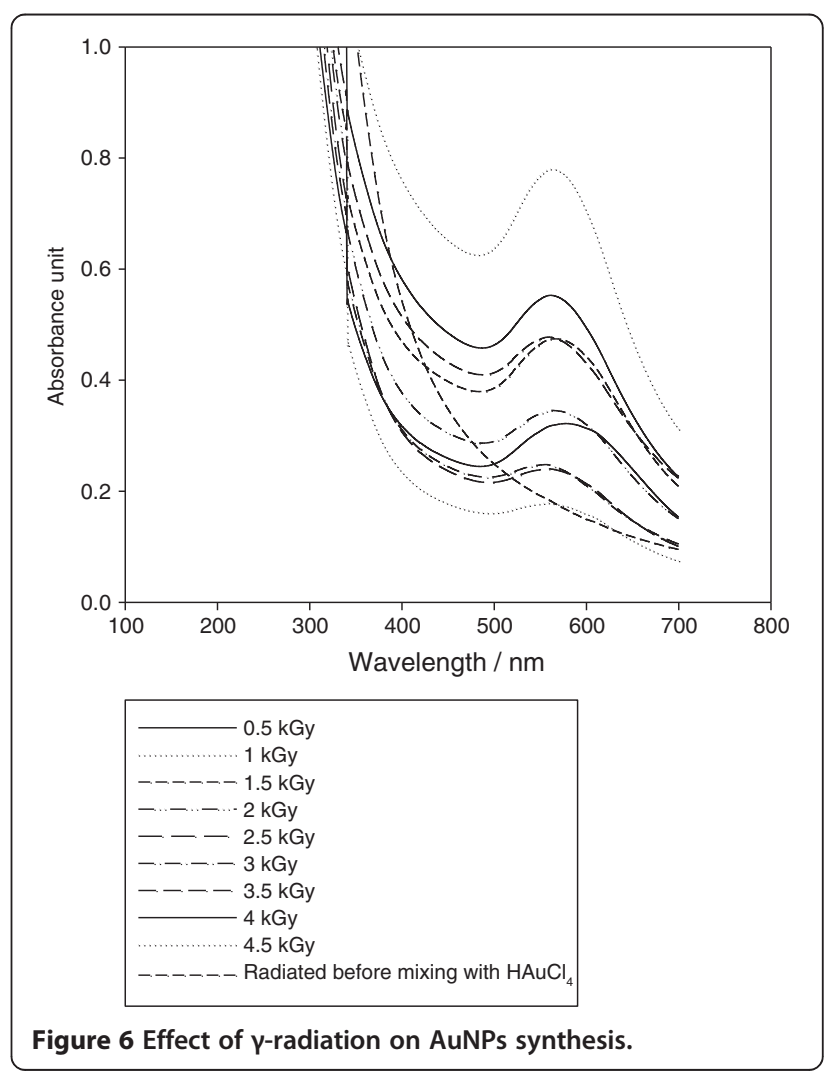


Table 2 The effect of radiation on total flavonoids

\begin{tabular}{ll}
\hline Radiation dose/kGy & $\begin{array}{l}\text { Total Flavonoids } \mathbf{m g} \text { rutin/gm } \\
\text { fermented product }\end{array}$ \\
\hline 0.5 & 0.49 \\
\hline 1 & 0.53 \\
\hline 1.5 & 0.46 \\
\hline 2.5 & 0.45 \\
\hline 3 & 0.44 \\
\hline 3.5 & 0.43 \\
\hline 4 & 0.42 \\
\hline 4.5 & 0.41 \\
\hline Control (not radiated) & 0.38 \\
\hline
\end{tabular}

Average particle size and size distribution were determined by PSS-NICOMP 380-ZLS particle sizing system St. Barbara, California, USA.

FT-IR measurements were carried out in order to obtain information about chemical groups present around AuNPs for their stabilization and understand the transformation of functional groups due to reduction process. The measurements were carried out using JASCO FT/IR-6300 infra-red spectrometer by employing $\mathrm{KBr}$ pellet technique.

The size and morphology of the synthesized nanoparticles were recorded by using TEM model JEOL electron microscope JEM-100 CX. TEM studies were prepared by drop coating $\mathrm{Au}$ nanoparticles onto carboncoated TEM grids. The film on the TEM grids were allowed to dry, the extra solution was removed using a blotting paper.

X-Ray Diffraction patterns were obtained with The XRD6000 series, including stress analysis, residual austenite quantitation, crystallite size/lattice strain, crystallinity calculation, materials analysis via overlaid X-ray diffraction patterns Shimadzu apparatus using nickel-filter and $\mathrm{Cu}-\mathrm{Ka}$ target, Shimadzu Scientific Instruments (SSI) ,Kyoto, Japan.

\section{Gamma irradiation source}

The process of irradiation was carried out at the National Center for Radiation Research and Technology (NCRRT), Egypt. The facility used was Co-60 Gamma chamber 4000-A-India. Irradiation was performed using Co-60 Gamma rays at a dose rate of $10.28 \mathrm{kGy} / \mathrm{hr}$ at the time of the experiment.

\section{Determination of total flavonoids}

Total flavonoids were estimated using the method of (Ordonez et al. 2006). To $0.5 \mathrm{ml}$ of sample, $0.5 \mathrm{ml}$ of $2 \%$ $\mathrm{AlCl}_{3}$ ethanolic solution was added. After one hour, at room temperature, the absorbance was measured at $\lambda 420 \mathrm{~nm}$ using (JASCO V-560 UV-visible spectrophotometer). 2A

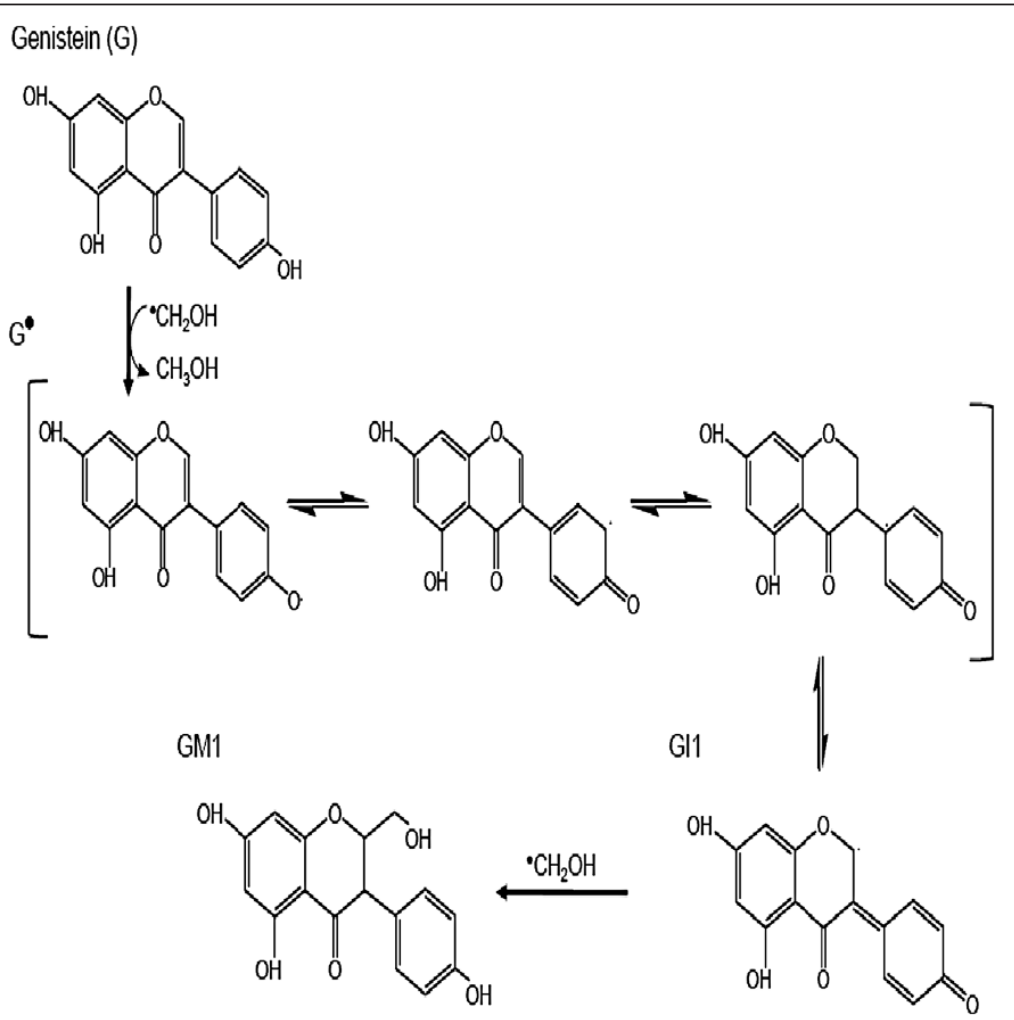

Figure 7 Radiolysis of genistein in methanolic solution by $\mathrm{Y}$-radiation. 
<smiles>CCON=O</smiles><smiles>CCOc1cc(O)cc2c1C(=O)CC(c1ccc(O)c(O)c1)O2</smiles>

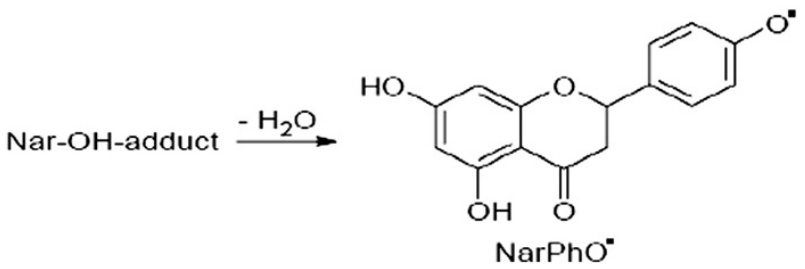

Figure 8 Radiolysis of narngenin in aqueous solution by $\mathrm{Y}$-radiation. Nar= narngenin.

yellow color indicates the presence of flavonoids. Total flavonoid contents were calculated as rutin mg equivalent per gm fermented product.

\section{Determination of total phenol}

Total phenolic content was determined by the Folin Ciocalteau colorimetric method of assay by (Singleton, et al. 1999). Briefly, $50 \mu \mathrm{l}$ of sample was mixed with $3 \mathrm{ml}$ of distilled water and $250 \mu \mathrm{l}$ of Folin reagent was added and immediately vortexed. Then, $750 \mu \mathrm{l}$ of saturated $\mathrm{Na}_{2} \mathrm{CO}_{3}$ solution was added. Then, adjust the final volume to $5 \mathrm{ml}$ using distilled water. Incubation for 2 hours at room temperature and then measure the absorbance at $765 \mathrm{~nm}$ against distilled water as blank. Total polyphenolic content is expressed as gallic acid mg equivalent.

\section{Antimicrobial sensitivity test}

The AuNPs synthesized was tested for antimicrobial activity by agar well diffusion method (Bauer et al., 1966) against different kinds of pathogenic bacteria and yeast isolated from clinical samples; Staphylococcus aureus MRSA (Gram positive bacteria), Pseudomonas aeruginosa and Acinetobacter baumaninii/ heamolyticus (Gram negative bacteria). Standardized suspension of each tested strain $10^{8}$

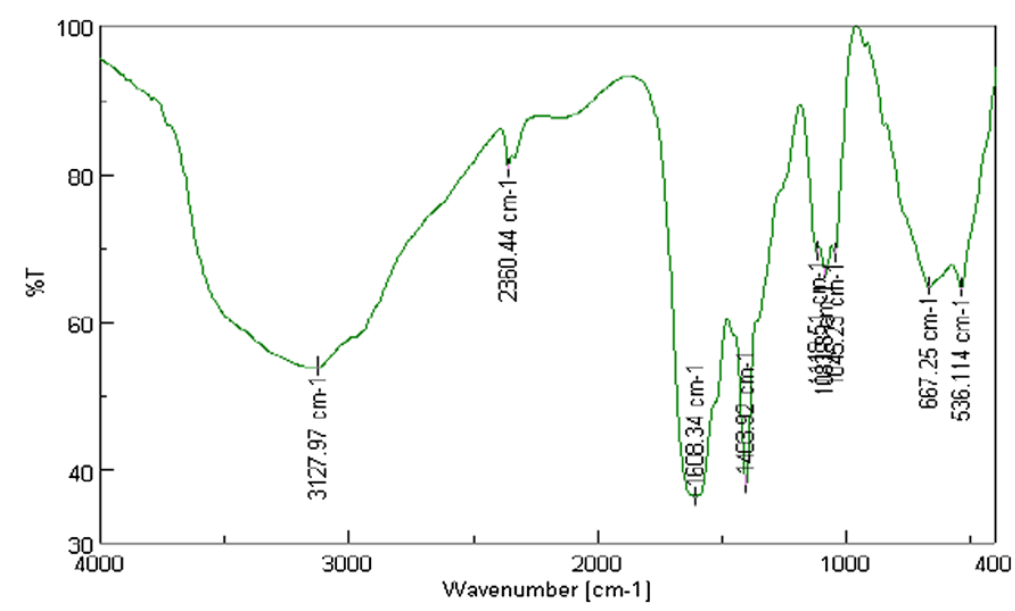

Figure 9 FT-IR spectra of fermented extract. 


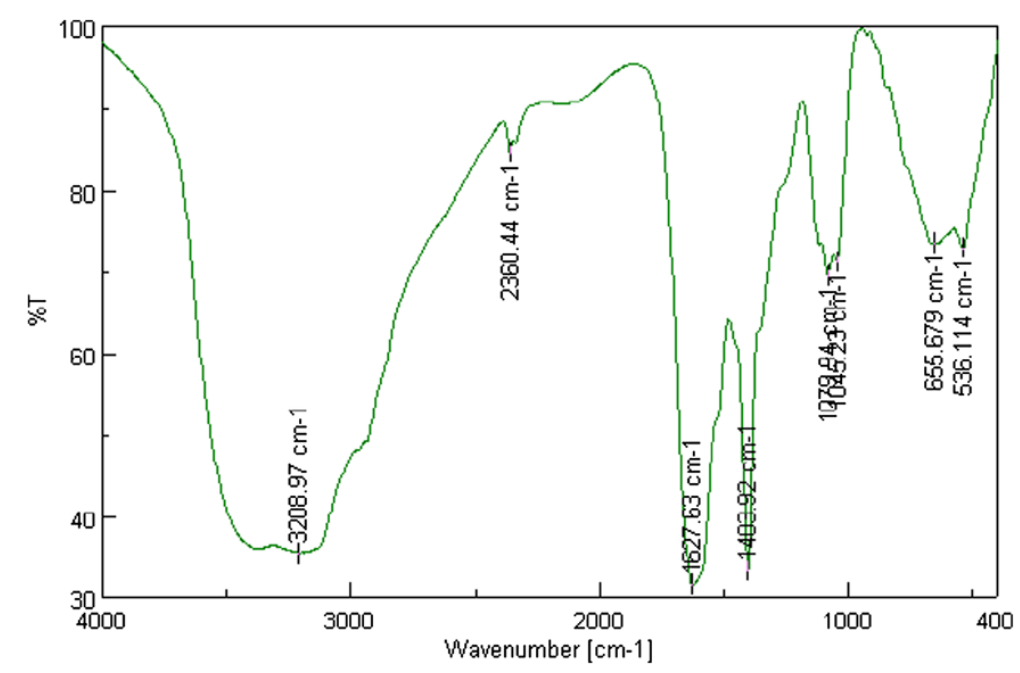

Figure 10 FT-IR spectra of fermented extract with AuNPs.

$\mathrm{CFU} / \mathrm{ml}$ for bacteria was swabbed uniformly onto sterile Muller-Hinton Agar (MHA) (Oxoid) plates using sterile cotton swab wells of $10 \mathrm{~mm}$ diameter were bored into the agar medium using gel puncture. Using a micropipette, 100 $\mu \mathrm{l}$ of the AuNPs solution (7.5 $\mathrm{mM} \mathrm{HAuCl}_{4}$ in $5 \mathrm{ml}$ extract) was added into each well. After incubation at $37^{\circ} \mathrm{C}$ for 24 hrs, the different levels of zone of inhibition were measured and interpreted using the CLSI zone diameter interpretive standards (CLSI, 2008). Tetracycline (antibacterial agent) served as positive control for antimicrobial activity, while the filtrate alone (without AuNPs) was used a negative control. The determinations were done in triplicates and the mean values \pm SD (standard deviation) were presented.

\section{Results and discussion}

\section{Preparation and characterization of AuNPs}

The aqueous fermented extract was used for the synthesis of AuNPs, since it is enriched with mobilized phenolic compounds which are responsible for both synthesis and stabliziation of AuNPs. The formation of AuNPs was monitored with the color change and UV-vis spectroscopy. The reaction started within seconds after addition of the reagents and the color changes from yellow to pink then violet, Figure 1. The color change is attributed to the surface plasmon resonance (SPR) (Mulvaney, 1996). A characteristic SPR band for AuNPs is obtained at around $\lambda 550 \mathrm{~nm}$.

The UV-vis spectra as a function of time, at a concentration of $7.5 \mathrm{mM}$ tetrachloroauric acid and $5 \mathrm{ml}$ of aqueous fermented extract, indicates that the reaction was completed during the first 5 minutes and further increase in time does not influence the formation of AuNPs. As described in Figure 2 almost same intensity of SPR band was obtained at 10, 15 and 25 minutes and the change only occurred at 5 minutes. These results are in agreement with those reported by (Noruzi et al. 2011). A higher intensity SPR band was obtained after 60 minutes, which indicates more formation of AuNPs but with much slower rate of reaction.

Table 3 Peaks appeared in FT-IR spectra for fermented extract with and without tetrachloroauric acid solution

\begin{tabular}{|c|c|c|c|}
\hline Peak no & Extract $\lambda\left(\mathrm{cm}^{-1}\right)$ & Extract + AuNPs $\lambda\left(\mathrm{cm}^{-1}\right)$ & Comment \\
\hline 1 & 3127.97 & 3208.97 & $\begin{array}{l}\text { The broad peaks are characteristic to the presence of }-\mathrm{NH}_{2} \text { amine group } \\
\text { and }-\mathrm{OH} \text { stretching groups in alcoholic and phenolic compounds. } \\
\text { Noruzi et al. 2011, increased intensity which may be due to binding } \\
\text { of gold ions to } \mathrm{OH} \text { group. Rastogi and Arunachalam } 2011\end{array}$ \\
\hline 2 & 2360.4 & 2360.4 & Corresponds to aliphatic C-H stretching. Noruzi et al. 2011 \\
\hline 3 & 1608.34 & 1627.63 & $\begin{array}{l}\text { Characteristic to the carbonyl group. This red shift may indicate oxidation } \\
\text { of carbonyl group during the reaction and hence reducing gold to AuNPs. } \\
\text { Rastogi and Arunachalam } 2011\end{array}$ \\
\hline 4 & 1403.92 & 1403.92 & $\begin{array}{l}\text { May be ascribed for the presence of primary amine group C-N } \\
\text { stretching. Kumar et al. } 2012\end{array}$ \\
\hline 6 & 1118.51 & 1079.91 & $\begin{array}{l}\text { May be attributed to } \mathrm{SO}_{2} \text { absorption of sulfones present in garlic. } \\
\text { Rastogi and Arunachalam } 2011\end{array}$ \\
\hline 7 & 667.25 & 655.67 & Signifies the presence of R-CH group Noruzi et al. 2011 \\
\hline
\end{tabular}




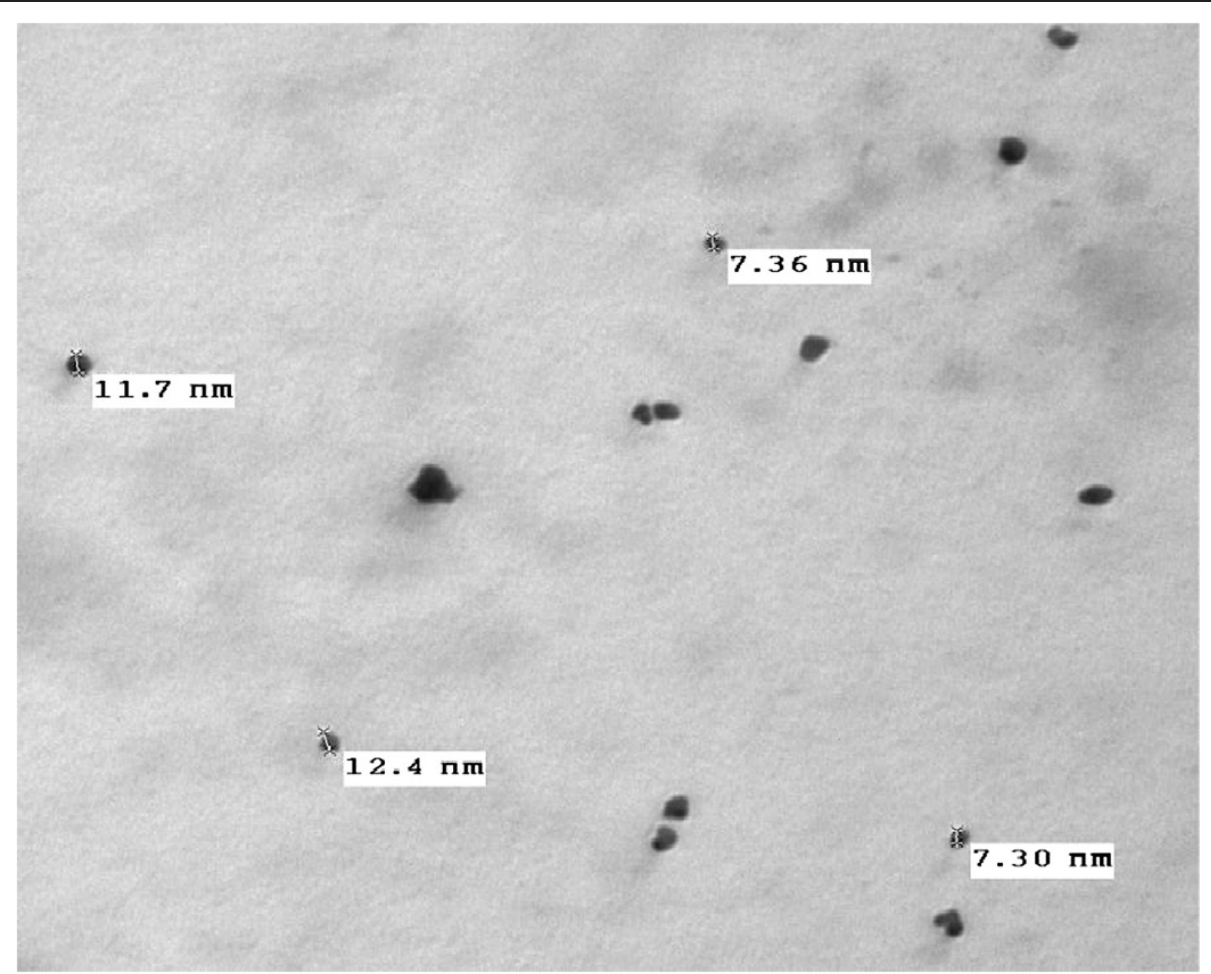

Figure 11 TEM image for AuNPs.

The effect of extract quantity indicates that only $5 \mathrm{ml}$ of the extract was enough to carry out the reaction at a concentration of $7.5 \mathrm{mM}$ of tetrachloroauric acid. As shown in Figure 3, the SPR band intensity decreases as the volume of extract increases to 5, 7.5, 10 and $15 \mathrm{ml}$ (containing $0.272 \mathrm{mg} / \mathrm{ml}$ total phenols expressed as gallic acid equivalent). The higher intensity was obtained at $5 \mathrm{ml}$ which indicates that $5 \mathrm{ml}$ was enough for the reaction and the SPR band intensity decreases due to dilution as the volume of extract increases, similar results were obtained by (Noruzi et al. 2011).

The concentration of tetrachloroauric acid added strongly affects the reaction. As shown in Figure 4, the SPR band intensity increases with increase in concentration $(2.5,5.7 .5$, $10 \mathrm{mM}$ ) in $5 \mathrm{ml}$ of fermented aqueous extract, which indicates increased rate of reaction by increasing the concentration of tetrachloroauric acid used, as reported earlier by (Noruzi et al. 2011) .

The effect of temperature was determined by carrying out the reaction using $(5 \mathrm{ml})$ of extract and $(7.5 \mathrm{mM})$ tetrachloroauric acid solution at different temperatures, namely; 25, 50, 75 and $100^{\circ} \mathrm{C}$. As shown in Table 1, it was found that as temperature increases, the AuNPs synthesis rate increases and the time taken for color conversion was much reduced. At $25^{\circ} \mathrm{C}$, there was an initial lag period for the formation of gold nuclei and the synthesis time was longer. There was final conversion to
AuNPs at all reaction temperatures after 2 hours as shown in Figure 5 with higher SPR band intensity at $100^{\circ} \mathrm{C}$ than at $25^{\circ} \mathrm{C}$ indicating more formation of AuNPs at high temperature.

The radiation-induced synthesis is one of the most promising strategies (Mostafavi et al. 1993). The process is simple, clean and has harmless feature. Exposure of the extract to different doses of radiation, namely; $0.5,1$, 1.5, 2, 2.5, 3, 3.5, 4 and $4.5 \mathrm{kGy}$ was performed after addition tetrachloroauric acid at concentration of 7.5 $\mathrm{mM}$ and $5 \mathrm{ml}$ of aqueous fermented extract. A blank was performed by exposing the filtrate to radiation before mixing with tetrachloroauric acid. SPR band was noted for all doses, maximum intensity was found at a dose of $1 \mathrm{kGy}$, after which further increase in radiation dose results in decrease in SPR band intensity, while no peak was recorded in blank sample (radiation before mixing with tetrachloroauric acid), Figure 6.

The formation of AuNPs can be attributed to the radiolytic reduction which generally involves radiolysis of aqueous solutions that provides an efficient method to reduce metal ions. In the radiolytic method, when aqueous solutions are exposed to gamma rays, they create solvated electrons, which reduce the metal ions and the metal atoms eventually coalesce to form aggregates (Marignier et al. 1985). The combined effect of both radiolytic reduction and presence of soybean flavonoids, 


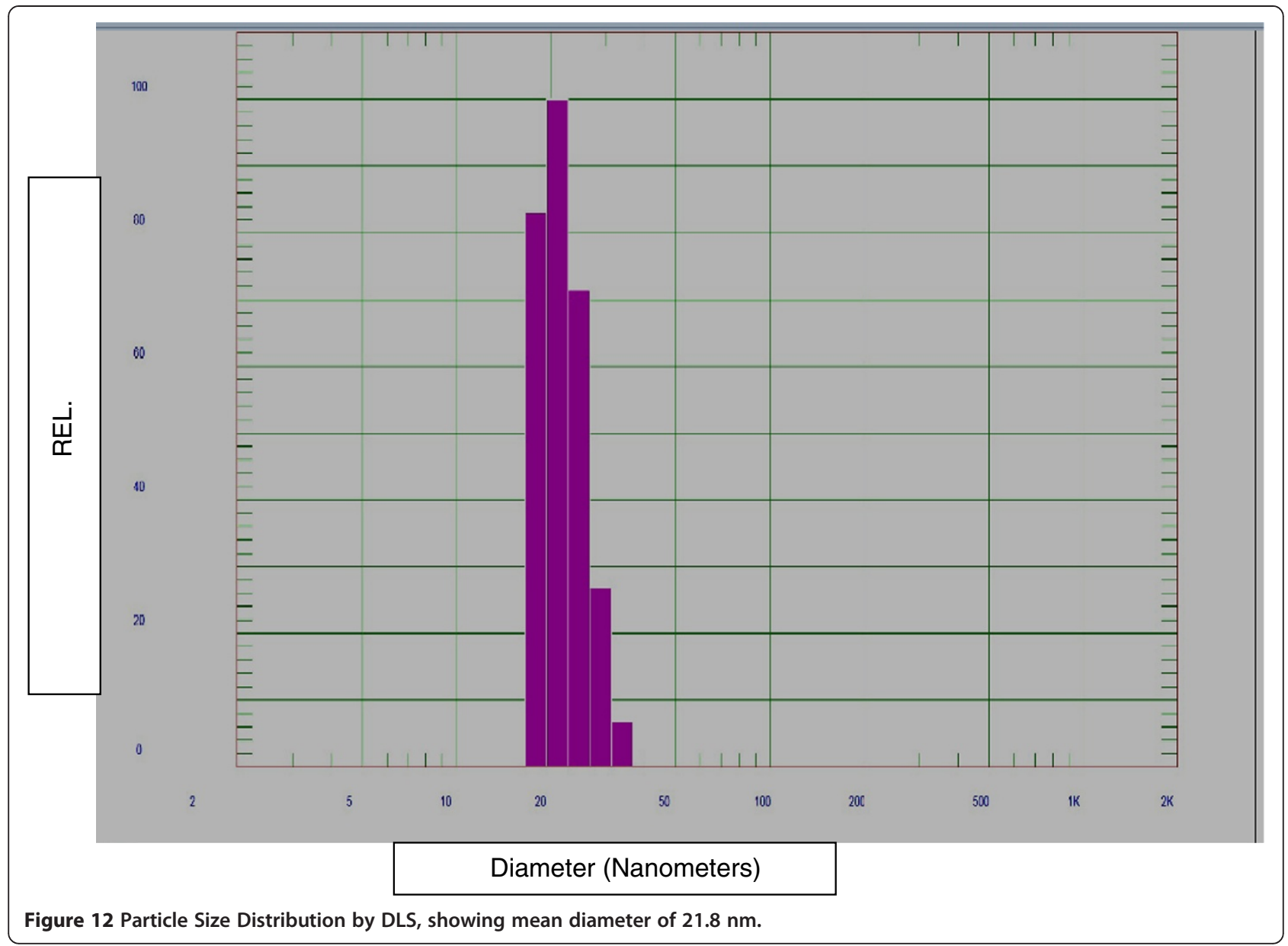

and sulfur containing compounds and proteins in garlic resulted in formation of AuNPs by radiolytic reactions and stabilization by prevention of aggregates formation by "capping". The decrease in the SPR band intensity by increasing the radiation dose more than $1 \mathrm{kGy}$ up to 4.5 kGy may be attributed to the destructive effect of free radicals produced by gamma radiation on the bioactive compounds present in the extract. It has been reported that a decrease in total isoflavones of soybean was noted with increased radiation dose from (0.5-5.0 kGy) (Variyar et al. 2004) which was confirmed by decrease in the total flavonoid content measured in the fermented extract as the dose of radiation increased Table 2. Exposure of water or aqueous solutions to ionizing radiation leads to formation of primary species $\mathrm{H}_{3} \mathrm{O}+\mathrm{H} \cdot \mathrm{H}, \mathrm{OH}$, $\mathrm{H}_{2} \mathrm{O}_{2}$. These free radicals have major importance in radiolytic chemical reactions of flavonoids. As explained by (Jovanovic, et al. 1994 and Rice-Evans et al. 1996), the antioxidant activity and hence reducing activity of flavonoids depends mainly on the presence of a catechol group in the B-ring, which has the best $\mathrm{H}$-transfer potential and the 2,3-double bond conjugated with the 4-oxo group, which is responsible for electron delocalization. Since the B-ring is electron richer than the A-ring of flavonoids, it is an apparent target of any antioxidant. Therefore, it can be assumed that the $\mathrm{OH}-$ attack takes place on B-ring. In both cases, the catechol group of B-ring is disrupted after attack of free-radicals and $\mathrm{C} 2-\mathrm{C} 3$ double bond in gensitein was affected after radiation. This degradation affects the reducing power of flavonoids and their ability to stabilize the AuNPs formed. The proposed mechanism for radiolysis of genistein in methanolic solution was previously reported by (Jung et al. 2009) as shown in Figure 7. Also, naringenin flavonoid radiolysis in aqueous solution was previously explained by (Nagy et al. 2008) as shown in Figure 8. The destruction of bioactive compounds by radiation results in less stabilized and less suspended AuNPs and encourages the formation of sediment aggregates which may explain the decrease in SPR band intensity.

The FT-IR spectra Figures 9 and 10, as explained in Table 3, indicates that the AuNPs synthesized using the soybean-garlic fermented extract are surrounded by proteins, sulfone groups and metabolites such as 


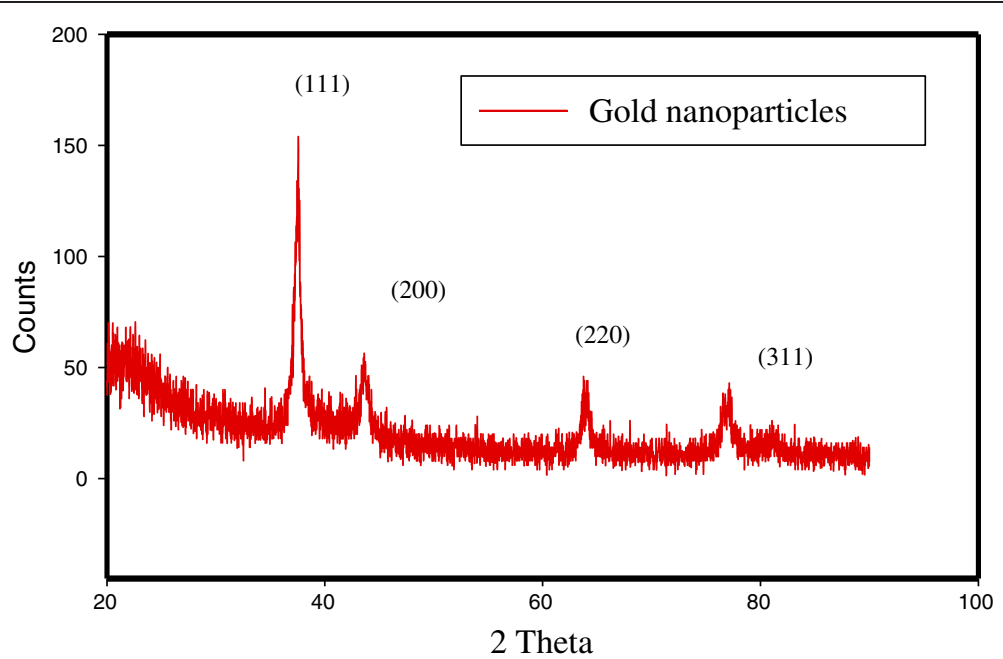

Figure 13 XRD spectrum of AuNPs.

polyphenols having functional groups of alcohols, amines and carbonyl which facilitate the reduction of gold ions to AuNPs. A redox type of process can be noticed where polyphenols oxidized to its quinone form followed by reduction of gold ions to AuNPs (Kumar et al. 2012).

TEM image in Figure 11 showed spherical AuNPs with size ranging from $7 \mathrm{~nm}$ to $12.4 \mathrm{~nm}$.

Average particle size was determined by DLS method and the mean diameter was found to be $21.8 \mathrm{~nm}$. The size distribution graph is shown in Figure 12.

For XRD analysis, the prepared sample was centrifuged and the precipitate was dried under vacuum and taken for XRD analysis. XRD pattern for the gold aggregates is shown in Figure 13, several peaks are observed, these being at $\mathrm{Au}$ nanocomposite show the diffraction features appearing at 2 theta (degree) as $38.2^{\circ}, 44.5^{\circ}, 64.7^{\circ}$, and $77.6^{\circ}$, which correspond to the (111), (200), (220), and (311) planes of the standard cubic phase of $\mathrm{Au}$, respectively. The XRD pattern indicated that gold nanoparticles were in the face-centered cubic (fcc) structure and crystal in nature.

The observation of diffraction peaks for the gold nanoparticles indicates that these are crystalline in this size range while its broadening is related to the particles in the nanometer size regime. The mean particle diameter of Au-NPs was calculated from the XRD patterns using the following Scherrer equation:

$$
D=\frac{K \lambda}{B 1 / 2 \cos \theta}
$$

Mean size $=50 \mathrm{~nm}$

\section{Antimicrobial assay}

The antimicrobial activity of green synthesized nanoparticles was tested by referring to tetracycline as a standard antibacterial agent. As shown in Table 4, the synthesized AuNPs was proved to have $56.42 \%, 59.5 \%$ and $64.19 \%$ inhibition for Staphylococcus aureus MRSA ( $\mathrm{Gm}+\mathrm{ve})$, Pseudomonas aeruginosa (Gm - ve) and Acinetobacter baumaninii/haemolyticus ( $\mathrm{Gm}$ - ve), respectively. It can be suggested that Gram negative Pseudomonas aeruginosa and Acinetobacter baumaninii/haemolyticus with thin cell wall are more susceptible to cell wall damage compared to Gram positive S. aureus with thick cell wall and therefore more inhibition was reported for Gram negative bacteria (Kumar et al. 2012). No activity was observed in case of fermented extract alone.

Table 4 Antimicrobial sensitivity test for AuNPs

\begin{tabular}{lll}
\hline Tested strain & $\begin{array}{l}\text { Tetracycline (standard } \\
\text { antibacterial agent) }\end{array}$ & $\begin{array}{l}\text { *Diameter of inhibition zone (mm) } \\
\text { produced by AuNPs }\end{array}$ \\
\hline Staphylococcus aureus MRSA (Gm +ve) & 26 & $14.67 \pm 0.58$ \\
\hline Pseudomonas aeruginosa $(G m-v e)$ & 28 & $16.67 \pm 1.15$ \\
\hline Acinetobacter baumaninii/haemolyticus (Gm - ve) & 27 \\
\hline
\end{tabular}

*Data represents three replicates for each tested strain \pm standard deviation. 


\section{Conclusions}

The fermented soybean-garlic aqueous extract enriched with mobilized polyphenols and proteins can be used for efficient green synthesis of stabilized AuNPs, due to the presence of functional groups, such as; carbonyl group, hydroxyl group, sulfones and amines by acting as reducing agents as well as "capping" agents for stabilization of the AuNPs.

The combined effect of both $\gamma$-radiation and mobilized polyphenolic compounds in synthesis and stabilization of AuNPs offers a highly efficient and inexpensive method which can be used in large scale production of AuNPs.

Moreover, synthesized AuNPs showed good antimicrobial activity leading to high potential uses in biological applications.

\section{Competing interests}

The authors declare that they have no competing interests.

\section{Authors' contribution}

A.I. El-Batal, AM Hashem and NM Abdelbaky participated in the design of the study, supervised the field work and data collection and took part in the evaluation of the results. All authors read and approved the final manuscript.

\section{Acknowledgements}

The authors would like to thank the Nanotechnology Research Unit (P.I. Prof. Dr. Ahmed El-Batal), Pharmaceutical Microbiology Lab, Drug Radiation Research Department, National Center for Research and Radiation Technology (NCRRT), Egypt, for financing and supporting this study under the project "Nutraceuticals and Functional Foods Production by using Nano/ Biotechnological and Irradiation Processes".

\section{Author details}

${ }^{1}$ Drug Radiation Research Department, National Center for Radiation Research \& Technology (NCRRT), P.O. Box 29, Nasr City, Cairo, Egypt. ${ }^{2}$ Microbiology \& Immunology Department, Faculty of Pharmacy, Cairo University, P.O. Box 11562, Kasr Al-Aini Street, Cairo, Egypt.

Received: 14 October 2012 Accepted: 15 March 2013

Published: 23 March 2013

\section{References}

Baschong W, Stierhof YD (1998) Preparation, use and enlargement of ultrasmall gold particles in immunoelectron microscopy. J Microsc Res Tech 42:66-79

Bauer AW, Kirby WM, Sherris JC, Turck M (1966) Antibiotic susceptibility testing by a standardized single disk method. Am J Clin Pathol 45:493-496

Bhanja T, Kumari A, Banerjee R (2009) Enrichment of phenolics and free radical scavenging property of wheat koji prepared with two filamentous fungi. J Bioresour Technol 100:2861-2866

Bielinska A, Eichman JD, Lee I, Baker JR, Balogh L (2002) Imaging Au-0-PAMAM gold dendrimer nanocomposites in cells. J Nanopart Res 4:395-403

CLSI (2008) Performance Standards for Antimicrobial Susceptibility Testing: Eighteenth Informational Supplement, 18th edn. Clinical and Laboratory Standard Institute, USA, p 181

Daniel MC, Astruc D (2004) Gold nanoparticles: assembly, supramolecular chemistry, quantum-size-related properties, and applications toward biology, catalysis, and nanotechnology. J Chem Rev 104:293-346

Gole A, Dash C, Ramakrishnan V, Sainkar SR, Mandale AB, Rao M, Sastry M (2001) Pepsin-gold colloid conjugates: preparation, characterization, and enzymatic activity. J Langmuir 17:1674-1679

Huang W, Niu H, Li Z, He Y, Gong W, Gong G (2008) Optimization of ellagic acid production from ellagitannins by co-culture and correlation between its yield and activities of relevant enzymes. J Bioresour Technol 99:769-775

Jo SK, Jung HJ, Jung U, Park HR, (2009) Radiolysis study of genistein in methanolic solution. J Radiat Phys Chem 78:386-393
Jovanovic SV, Steenken S, Tosic M, Marjanovic B, Simic MG (1994) Flavonoids as antioxidants. J Am Chem Soc 116:4846-4851

Kumar KM, Mandal BK, Sinha M, Krishnakumar V (2012) Terminalia chebula mediated green and rapid synthesis of gold nanoparticles. J Spectrochimica Acta Part A 86:490-494

Lee Y-L, Yang J-H, Mau J-L (2008) Antioxidant properties of water extracts from Monascus fermented soybeans. J Food Chem 106:1128-1137

Li T, Park HG, Choi S-H (2007) Y-Irradiation-induced preparation of Ag and Au nanoparticles and their characterizations. J Mater Chem and Physi 105:325-330

Marignier JL, Belloni J, Delcourt MO, Chevalier JP (1985) Microaggregates of nonnoble metals and bimetallic alloys prepared by radiation-induced reduction. J Nature 317:344-345

Mathew S, Abraham TE (2006) Studies on the antioxidant activities of cinnamon (Cinnamomum vermum) bark extract, through various in vitro models. J Food Chem 94:520-528

McCue P, Horii A, Shetty K (2003) Solid state bioconversion of phenolic antioxidants from defatted soybean powders by Rhizopus oligosporus: role of carbohydrate cleaving enzymes. J Food Biochem 17:499-512

McCue PP, Shetty K (2005) A model for the involvement of lignin degradation enzymes in phenolic antioxidant mobilization from whole soybean during solid state bioprocessing by Lentinus edodes. J Proc Biochem 40:1791-1797

Mostafavi M, Delcourt MO, Picq G (1993) Study of the interaction between polyacrylate and silver oligomer clusters. J Radiat Phys Chem 41:453-459

Mulvaney P (1996) Surface plasmon spectroscopy of nanosized metal particles. Langmuir 12:788-800

Nagy TO, Ledolter K, Solar S (2008) Oxidation of naringenin by gamma radiation. J Radiat Phys Chem 77:728-733

Nam JM, Thaxton CA (2003) Nanoparticle-based bio-bar codes for the ultrasensitive detection of proteins. J Sci 301:1884-1886

Noruzi M, Zare D, Khoshnevisan K, Davoodi D (2011) Rapid green synthesis of gold nanoparticles using Rosa hybrida petal extract at room temperature. J Spectrochimica Acta Part A 79:1461-1465

Ordonez AAL, Gornez JG, Vattuone MA, Isla MI (2006) Antioxidant activities of Sechium edule Swart extract. J Food Chem 97:452-458

Paciotti GF, Myer L, Weinreich D, Goia D, Pavel N, McLaughlin RE, Tamarkin L (2004) Colloidal gold: a novel nanoparticle vector for tumor directed drug delivery. J Drug Deliv 11:169-183

Penn SG, He L, Natan M (2003) Nanoparticles for bioanalysis. J Curr Opin Chem Biol 7:609-615

Prow T, Smith JN, Grebe R, Salazar JH, Wang N, Kotov N, Lutty G, Leary J (2006) Construction, gene delivery and expression of DNA tethered nanoparticles. J Mol Vis 12:606-615

Rastogi L, Arunachalam J (2011) Sunlight base irradiation strategy for rapid green synthesis of the highly stable silver nanoparticles using aqueous garlic (Allium sativum) extract and their antibacterial potential. J Mater Chem and Physi 129:558-563

Rice-Evans CA, Miller NJ, Paganga G (1996) Structure-antioxidant activity relationships of flavonoids and phenolic acids. Free Radic Biol Med 20:933-956

Roth J (2003) Protien glycosylation in the endoplasmic reticulum and the Golgi apparatus and cell type specificity of cell surface glycoconjugate expression: analysis by the protein A-gold and lectin-gold techniques. J Histochem Cell Biol 7:609-615

Shukla R, Bansal V, Chaudhary M, Basu A, Bhonde RR, Sastry M (2005) Biocompatibility of gold nanoparticles and their endocytotic fate inside the cellular compartment: a microscopic overeview. Langmuir 21:10644-10654

Singleton VL, Orthofer R, Lamuela-Raventos RM (1999) Analysis of total phenols and other oxidation substrates and antioxidants by means of Folin-Ciocalteu reagent. Methods Enzymol 29:152-178

Song JY, Kim BS (2009) Rapid biological synthesis of silver nanoparticles using plant leaf extract. J Bioprocess Biosyst Eng 32:79-84

Tortora GJ, Funke BR, Case CL (2004) Microbiology an introduction, 8th edn. Pearson Education Private Limited, Singapore

Variyar PS, Limaye A, Sharma A (2004) Radiation-induced enhancement of antioxidant contents of soybean (Glycine max Merrill). J Agri and Food Chem 52:3385-3388

doi:10.1186/2193-1801-2-129

Cite this article as: El-Batal et al:: Gamma radiation mediated green synthesis of gold nanoparticles using fermented soybean-garlic aqueous extract and their antimicrobial activity. SpringerPlus 2013 2:129. 